\title{
Ligand determinants of fatty acid activation of the pronociceptive ion channel TRPA1
}

Background and Purpose Arachidonic acid (AA) and its derivatives are important modulators of cellular signalling. The transient receptor potential cation channel subfamily A, member 1 (TRPA1) is a cation channel with important functions in mediating cellular responses to noxious stimuli and inflammation. There is limited information about the interactions between AA itself and TRPA1, so we investigated the effects of AA and key ethanolamide and amino acid/neurotransmitter derivatives of AA on hTRPA1.

Experimental Approach HEK 293 cells expressing hTRPA1 were studied by measuring changes in intracellular calcium $\left([\mathrm{Ca}]_{\mathrm{i}}\right)$ with a fluorescent dye and by standard whole cell patch clamp recordings.

Key Results AA (30 $\mu \mathrm{M})$ increased fluorescence in hTRPA1 expressing cells by $370 \%$ (notional $\left.E C_{50}, 13 \mu \mathrm{M}\right)$. The covalent TRPA1 agonist cinnamaldehyde $(300 \mu \mathrm{M})$ increased fluorescence by $430 \%\left(E C_{50}, 11 \mu \mathrm{M}\right)$. Anandamide $(230 \%)$ and $\mathrm{N}$-arachidonoyl tyrosine (170\%) substantially activated hTRPA1 at $30 \mu \mathrm{M}$, however, $N$-arachidonoyl conjugates of glycine and taurine were less effective while $\mathrm{N}$-acyl conjugates of 5-HT did not affect hTRPA1. Changing the acyl chain length or the number and position of double bonds reduced fatty acid efficacy at hTRPA1. Mutant hTRPA1 (Cys621, Cys641 and Cys665 changed to Ala) could be activated by $\mathrm{AA}(100 \mu \mathrm{M}, 40 \%$ of wild type) but not by cinnamaldehyde $(300 \mu \mathrm{M})$.

Conclusions and Implications AA is a more potent activator of TRPA1 than its ethanolamide or amino acid/neurotransmitter derivatives and acts via a mechanism distinct from that of cinnamaldehyde, further underscoring the likelyhood of multiple pharmacologically exploitable sites on hTRPA1. 
1 William J Redmond ${ }^{1}$, Liquong $\mathrm{Gu}^{2}$, Maxime Camo ${ }^{1}$, Peter McIntyre ${ }^{2,3}$ Mark Connor ${ }^{1,4}$

2 ' ${ }^{1}$ Australian School of Advanced Medicine, Macquarie University, NSW

$3{ }^{2}$ Department of Pharmacology, University of Melbourne, Parkville, Victoria

$4{ }^{3}$ Health Innovations Research Institute, School of Medical Sciences, RMIT University, Bundoora,

5 Victoria

$6 \quad{ }^{4}$ Corresponding Author: Mark Connor

7 Australian School of Advanced Medicine,

8 Macquarie University

9 NSW, 2109

10 Australia 


\section{Abbreviations}

12 AA

13 AEA

14 AITC

$15 \mathrm{CA}$

$16[\mathrm{Ca}]_{\mathrm{i}}$

17 DHA

18 HBS

19 hTRPA1

20

21 NAAN

22 NA-5HT

23 NA-DA

24 NA-Gly

25 NA-Tyr

26 NA-Tau

27 NPPB arachidonic acid (20:4 $\omega 6)$

arachidonoyl ethanolamide

allyl isothiocyanate

cinnamaldehyde

intracellular calcium

docosohexaenoic acid

HEPES buffered saline

human transient receptor potential cation

channel subfamily A, member 1

$\mathrm{N}$-acyl neurotransmitter/amino acid conjugate

$N$-arachidonoyl serotonin

$N$-arachidonoyl dopamine

$N$-arachidonoyl glycine

$N$-arachidonoyl tyrosine

$N$-arachidonoyl taurine

5-Nitro-2-(3phenylpropylamino)benzoic acid 
Introduction

29 The transient receptor potential ankyrin 1 channel (TRPA1; Alexander et al., 2011; Corey et al.,

30 2003) is expressed on primary afferent nociceptors where it detects potentially damaging

31 environmental stimuli such as noxious cold, changes in $\mathrm{pH}$, noxious chemicals and endogenous

32 products of inflammation. Although there is emerging evidence for physiological roles of TRPA1

33 in cells intrinsic to brain and spinal cord (Shigetomi et al., 2011; Cho et al., 2012) and TRPA1 is

34 also expressed in the hair cells of the ear (Corey et al, 2004), most effects of TRPA1 ligands have

35 been linked with the expression of the channel in the peripheral sensory neurons of the dorsal

36 root, trigeminal and nodose ganglia (Nagata et al., 2005; Story et al., 2003).

37 Although a complete description of how TRPA1 is activated by such a wide variety of modulators

38 is yet to be realized, electrophilic agonists such as cinnamaldehyde (CA) and allyl isothiocyanate

39 (AITC) activate TRPA1 via reversible or irreversible covalent modification of cysteine residues

40 located within the intracellular N-terminal domain (Hinman et al., 2006; Macpherson et al.,

41 2007). The mechanism(s) underlying the activation of TRPA1 by unreactive compounds such as

42 menthol (Karashima et al., 2007), 5-nitro-2-(3-phenylpropylamino)benzoic acid (NPPB) (Liu et

43 al., 2010) and $\Delta^{9}$-tetrahydrocannabinol (Jordt et al., 2004) are less well described, although in

44 some cases residues in transmembrane domains appear to be important for channel activation by

45 these ligands (e.g. menthol, Xiao et al., 2008). Intriguingly, mutation of cysteine residues which

46 abolish TRPA1 activation by electrophiles appears to also reduce the effectiveness of TRPA1

47 activation by most unreactive compounds, implying an important general role for these cysteine

48 residues in channel function. For example, a mutagenesis study by Liu (Liu et al., 2010) showed

49 that reactive and non-reactive compounds such as NPPB saw their peak $\left[\mathrm{Ca}_{\mathrm{i}}\right]$ response reduced

50 for single cysteine mutations to a serine. Xiao described that these residues are important for the 
51 activation of the channel mediated by menthol, another non-reactive compound (Xiao et al.,

52 2009). A requirement for formation of disulphide bonds between cysteine residues during

53 channel activation, including activation by non-reactive compounds, might explain why

54 there is lessened activity in the 3x Cys mutants (Wang et al., 2012).

55 TRPA1 is activated by arachidonic acid-derived molecules, including highly reactive 56 isoprostanes, prostaglandins (Taylor-Clark et al., 2008), hepoxilins (Gregus et al., 2012), 57 epoxyeicosatreinoic acids (Sisignano et al., 2012) and the endocannabinoid anandamide (De 58 Petrocellis et al., 2009). Arachidonic acid (AA) itself has also been reported to activate TRPA1

59 (Bandell et al. 2004, Motter et al. 2012). In this study we have examined the activation of 60 recombinant human TRPA1 (hTRPA1) by arachidonic acid and other long chain fatty acids as

61 well as by $N$-arachidonoyl neurotransmitter/amino acid conjugates (NAAN), a large family of 62 endogenous modulators of ion channels and G protein coupled receptors (Connor et al., 2010).

63 We find that AA itself is the most effective activator of hTRPA1 among these compounds, and

64 modest changes in its structure dramatically alter TRPA1 activity. Mutations in the intracellular

65 Cys residues that essentially abolish the activity of CA also reduce the effects of AA, suggesting

66 some overlap in the mechanisms through which diverse agonists activate the channel.

\section{Methods}

\section{Cell culture}

69 Flp-In TRex HEK 293 (Life Technologies, Mulgrave, Victoria, Australia) were stably transfected 70 with wild type or mutant hTRPA1 or wild type mouse TRPA1 (Genscript, Piscataway, NJ, USA)

71 and cultivated in Dulbecco's modified Eagle's Medium supplemented with $10 \%$ fetal bovine 72 serum, $100 \mathrm{U}$ penicillin and $100 \mu \mathrm{g}$ streptomycin $\mathrm{ml}^{-1}$, hygromycin B $25 \mu \mathrm{g} \mathrm{ml}^{-1}$ and blasticidin S 
$735 \mu \mathrm{g} / \mathrm{ml}^{-1}$. Cells were incubated in $5 \% \mathrm{CO}_{2}$ at $37^{\circ} \mathrm{C}$ in a humidified atmosphere. Cells were

74 grown in flasks with a surface area of $75 \mathrm{~mm}^{2}$, once at optimum confluence (approximately 90

$75 \%$ ), cells were trypsinized and transferred into clear-bottomed poly-D-lysine coated 96 well

76 plates (Corning, Castle Hill, NSW, Australia) in L15 medium supplemented with 1\% fetal bovine

77 serum, hygromycin B, and the antibiotics outlined above. The cells were plated in a volume of

$78100 \mu \mathrm{L}$ and were incubated in humidified room air at $37^{\circ} \mathrm{C}$ overnight. Expression of the TRPA1

79 receptor or mutants was induced 5-8 hours prior to experimentation by addition of with

80 tetracycline, $1 \mu \mathrm{g} \mathrm{ml}^{-1}$ to each well.

\section{Calcium assay}

82 Intracellular calcium $[\mathrm{Ca}]_{\mathrm{i}}$ was measured with the calcium 5 kit from Molecular Devices

83 (Sunnyvale, CA, USA) using a FLEX Station 3 Microplate Reader (Molecular Devices,

84 Sunnyvale, CA, USA). $100 \mu \mathrm{l}$ of dye dissolved in HEPES- buffered saline (HBS) containing (in

$85 \mathrm{mM}$ ): $\mathrm{NaCl}$ 140, $\mathrm{KCl} 5.33, \mathrm{CaCl}_{2}$ 1.3, $\mathrm{MgCl}_{2}$ 0.5, HEPES 22, $\mathrm{Na}_{2} \mathrm{HPO}_{4}$ 0.338, $\mathrm{NaHCO}_{3} 4.17$,

$86 \mathrm{KH}_{2} \mathrm{PO}_{4} 0.44, \mathrm{MgSO}_{4}$ 0.4, glucose 10 ( $\mathrm{pH}$ to 7.3 , osmolarity $=330 \pm 5$ mosmol) was loaded into

87 each well of the plate for 1 hour prior to testing in the Flexstation at $37^{\circ} \mathrm{C}$. Fluorescence was

88 measured every 2 seconds $\left(\lambda_{\text {excitation }}=485 \mathrm{~nm}, \lambda_{\text {emission }}=525 \mathrm{~nm}\right)$ for the duration of the experiment.

89 Drugs were added after at least 2 minutes of baseline recording. In experiments where one drug

90 addition was made, $50 \mu \mathrm{L}$ of drug dissolved in HBS was added, for two drug additions, $25 \mu \mathrm{L}$

91 was added each time.

\section{Electrophysiology}

93 TRPA1 channel currents in HEK293 cells were recorded in the whole-cell configuration of the 94 patch-clamp method (Hamill et al., 1981) at room temperature. Dishes were perfused with 95 HEPES buffered saline (HBS) containing (in mM): $140 \mathrm{NaCl}, 2.5 \mathrm{KCl}, 2.5 \mathrm{CaCl}_{2}, 1 \mathrm{MgCl}_{2} .10$ 
96 HEPES, 10 Glucose ( $\mathrm{pH}$ to 7.3 , osmolarity $=330 \square 5$ mosmol). Recordings were made with

97 fire-polished borosilicate glass pipettes with resistance ranging from 2-3 M $\Omega$. The internal 98 solution contained (in $\mathrm{mM}$ ): $130 \mathrm{CsCl}, 10 \mathrm{HEPES}, 2 \mathrm{CaCl}_{2}, 10 \mathrm{EGTA}, 5 \mathrm{MgATP}$ (pH to 7.3, 99 osmolarity $=285 \square 5$ mosmol). Recordings were made with a HEKA EPC 10 amplifier with 100 Patchmaster acquisition software (HEKA Elektronik, Germany). Data was sampled at $10 \mathrm{kHz}$, 101 filtered at $3 \mathrm{kHz}$, and recorded on hard disk for later analysis. Series resistance ranged from 3 to

$10210 \mathrm{M} \Omega$, and was compensated by at least $80 \%$ in all experiments. Leak subtraction was not used. 103 Cells were exposed to drugs via flow pipes positioned approximately $200 \mu \mathrm{m}$ from the cell, drugs 104 were dissolved in HBS immediately before application. All solutions had final ethanol 105 concentration of $0.05 \%$ to $0.1 \% \mathrm{v} / \mathrm{v}$.

\section{Data analysis}

107 The response to agonists was expressed as a percentage change over the baseline averaged for the 10830 seconds immediately prior to drug addition. Changes produced by parallel solvent blanks 109 were subtracted before normalization, these changes were never more than $10 \%$ of baseline. 110 Concentration-effect data were fit to a four-parameter logistic Hill equation to derive the $\mathrm{EC}_{50}$

111 values and Hill slope (GraphPad Prism, San Diego, CA). Where solubility precluded determining

112 full concentration response curves, the curve maxima were constrained to the maximum increase 113 in $[\mathrm{Ca}]_{\mathrm{i}}$ produced by a high concentration of cinnamaldehyde in the same experiment. In these 114 cases drug potency was reported as a notional $\mathrm{EC}_{50}$. Comparisons between human and mouse 115 TRPA1 were made after normalising responses to those produced by a maximally effective 116 concentration of CA $(300 \mu \mathrm{M})$ included in each experiment. Results are expressed as mean \pm 117 s.e.m. of at least 4-5 independent determinations. 
119 All drugs were made up in ethanol and diluted in HBS to give a final concentration of ethanol of

$120 \quad 0.05-0.1 \%$. Because of limits to the solubility of fatty acids and their derivatives, the maximum

121 concentration used was either $30 \mu \mathrm{M}$ or $100 \mu \mathrm{M}$, as noted. Arachidonic acid and its derivatives

122 were purchased from Cayman Chemical (Ann Arbor, MI, USA) and NAAN were purchased from 123 Biomol (Plymouth Meeting, PA, USA) or Cayman Chemicals. NPPB was purchased from Tocris

124 Bioscience (Bristol, UK), ruthenium red from Enzo Lifesciences (Farmingdale, NY, USA), HC 125030031 and ionomycin were from Ascent Scientific (Avonmouth, UK). Cinnamaldehyde was 126 purchased from Sigma-Aldrich (Castle Hill, NSW, Australia). All tissue culture reagents were 127 from Sigma-Aldrich, Life Technologies (Mulgrave, Victoria, Australia) or Invivogen, (San Diego, 128 CA, USA).

129 To independently confirm the activity of adrenic acid and $\omega 3$-arachidonic acid, we compared 130 their effects on $\mathrm{Ca}_{\mathrm{v}} 3.1$ calcium channels with those of $\omega 6$-arachidonic acid. Recordings from $131 \mathrm{Ca}_{\mathrm{V}} 3.1$ channels were made as described in Gilmore et al., (2012). Cells were stepped 132 repetitively from $-86 \mathrm{mV}$ to $-26 \mathrm{mV}$ for $20 \mathrm{~ms}$ every $10 \mathrm{~s}$. At a concentration of $10 \mu \mathrm{M}(\mathrm{n}=3$ 133 each), adrenic acid (64 $\pm 8 \%), \omega 3$-arachidonic acid $(43 \pm 5 \%)$ and $\omega 6$-arachidonic acid $(81 \pm 4 \%)$ 134 all inhibited $\mathrm{Ca}_{\mathrm{v}} 3.1$ channels to a degree consistent with previous reports of fatty acid activity on 135 this channel (Chemin et al., 2007).

\section{RESULTS}

137 Arachidonic acid has previously been reported to activate mouse and rat TRPA1 expressed in 138 Chinese hamster ovary and HEK 293 cells respectively (Bandell et al., 2004; Motter and Ahern, 139 2012). Addition of AA to HEK 293 cells expressing hTRPA1 produced rapid and sustained 
140 elevations of $[\mathrm{Ca}]_{\mathrm{i}}$. The increase was concentration-dependent, in our initial series of

141 experiments AA $(30 \mu \mathrm{M})$ increased cellular fluorescence by $369 \pm 38 \%$ over baseline with a 142 notional $E C_{50}$ of $13 \pm 4 \mu \mathrm{M}(\mathrm{n}=5)$. Concentration-response curves were fitted based on the 143 assumption that AA had a similar effect to the highest concentration of CA we used in our 144 experiments. Cinnamaldehyde (Bandell et al., 2004) activated hTRPA1 with an $E C_{50}$ of $11 \pm 2$ $145 \mu \mathrm{M}$, producing a maximum change of fluorescence of $431 \pm 29 \%$ at $300 \mu \mathrm{M}(\mathrm{n}=8)$ (Figure 1). We 146 were reluctant to use higher concentrations of CA because of the possibility of unspecific effects 147 on the cells. Since these studies were completed, it has been reported that at concentration higher 148 than $300 \mu \mathrm{M}, \mathrm{CA}$ has complex effects on TRPA1 reflecting both activation and inhibition of the 149 channel (Alpizar et al., 2013). It is not possible to study this complexity using our experimental 150 design. In our experiments, CA provides a constant reference response between experiments. 151 Addition of the non-selective antagonist of TRPA1, ruthenium red $(10 \mu \mathrm{M})$, largely blocked the 152 increase of $[\mathrm{Ca}]_{\mathrm{i}}$ caused by AA $(30 \mu \mathrm{M})$ and CA $(300 \mu \mathrm{M})$ (Figure 2$)$. The specific antagonist of 153 TRPA1, HC-030031 $(30 \mu \mathrm{M})$ abolished the responses to $10 \mu \mathrm{M}$ AA and $30 \mu \mathrm{M}$ CA (Figure 2).

154 Cells that were not incubated with tetracycline 4-8 hours prior to experimentation showed highly 155 attenuated responses (Figure 2). In order to test whether saturation of dye responses occurred 156 during experiments, the effects of ionomycin $(3 \mu \mathrm{M})$, an ionophore which elevates $[\mathrm{Ca}]_{\mathrm{i}}$, were 157 determined. The responses to the highest concentrations of CA (300 $\mu \mathrm{M})$ and AA $(100 \mu \mathrm{M})$ 158 tested were on average $63 \pm 7 \%$ and $55 \pm 6 \%$ of the response to $3 \mu \mathrm{M}$ ionomycin, respectively. 159 This indicates that the maximal TRPA1-mediated signal in our cells does not saturate the reporter 160 dye and that we are working within the dynamic range of our experimental system.

161 To confirm that AA and CA were activating a membrane conductance, whole cell voltage clamp 162 recordings were made from hTRPA1 HEK 293 cells induced overnight with a low concentration 163 of tetracycline $\left(1 \mu \mathrm{g} \mathrm{mL} \mathrm{m}^{-1}\right)$. Whole currents were elicited by repeatedly ramping the membrane 
164 potential of the cells from $-80 \mathrm{mV}$ to $+80 \mathrm{mV}$ over $500 \mathrm{~ms}$. The holding potential was $0 \mathrm{mV}$.

165 AA $(10 \mu \mathrm{M})$ produced a rapid increase in membrane current measured at $+80 \mathrm{mV}$ (from a 166 baseline of $280 \pm 10 \mathrm{pA}$ to a peak of $3.6 \pm 1.0 \mathrm{nA}, \mathrm{n}=6$, Figure 3) that was blocked by co-

167 incubation of the cells with ruthenium red $(\mathrm{RR}, 10 \mu \mathrm{M}$; control $340 \pm 9 \mathrm{pA}$; in AA and RR $247 \pm$ $1686 \mathrm{pA}, \mathrm{n}=6)$. Superfusion of the cells with CA $(100 \mu \mathrm{M})$ produced a similar current (baseline 306 $169 \pm 8$ pA, peak $4.6 \pm 1.5 \mathrm{nA}, \mathrm{n}=5$, Figure 3$)$.

170 Arachidonic acid can be metabolized to a number of molecules that activate TRPA1. To address

171 the possibility that AA metabolites were mediating the observed effects, we preincubated cells 172 with inhibitors of fatty acid amide hydrolase (FAAH), lipoxygenases and cyclooxygenases. $N$ 173 arachidonoyl serotonin (NA-5HT, FAAH, Maione et al., 2007), caffeic acid, (lipoxygenases, 174 Koshihara et al., 1983) and aspirin (cyclooxygenase, Vane, 1971) were used at a concentration of $17510 \mu \mathrm{M}$ and preincubated with the cells for 10 minutes before an addition of $10 \mu \mathrm{M}$ arachidonic 176 acid. The effect of AA was not altered by application of these enzyme inhibitors, $(\mathrm{P}>0.3$ for 177 each; Figure 4), leading us to believe that the activation of TRPA1 by AA was direct, and not due 178 to its modification via any of its main metabolic pathways.

179 We next examined the structural features of arachidonic acid (20:4 $\omega 6)$ relevant to TRPA1 180 activation. The relative insolubility of fatty acids meant that determining the maximal possible 181 activation of TRPA1 for most compounds was not possible, and so we chose a fixed 182 concentration of $30 \mu \mathrm{M}$ to make comparisons with. Increasing or decreasing the degree of 183 saturation on the fatty acid chain substantially or changing the acyl chain length reduced the 184 capacity of the ligand to activate hTRPA1. Docosahexaenoic acid (DHA 22:6 w3) and linoleic 185 acid (18:2 $\omega 6)$ produced modest elevations of $[\mathrm{Ca}]_{\mathrm{i}}$ in hTRPA1-expressing HEK 293 cells when 
186 applied at $30 \mu \mathrm{M}$ (Table 1). Adrenic acid (22:4 $\omega 6)$, oleic acid (18:1 cis- $\omega 9)$ and elaidic acid

$187(18: 1$ trans- $\omega 9)$ produced changes in $[\mathrm{Ca}]_{\mathrm{i}}$ of less than $20 \%$ at $30 \mu \mathrm{M}$. Arachidonic acid methyl 188 ester $(30 \mu \mathrm{M})$ produced similar elevations of $[\mathrm{Ca}]_{\mathrm{i}}$ to $\mathrm{AA}(30 \mu \mathrm{M})$ (Table 1$)$, however, 189 arachidonic acid ethyl ester $(30 \mu \mathrm{M})$ was essentially devoid of agonist activity at hTRPA1. 190 Interestingly, $\omega 6$-arachidonic acid had a greater agonist activity at hTRPA1 than $\omega 3$-arachidonic 191 acid (Table 1).

192 The first characterization of AA activation of TRPA1 was performed largely with mTRPA1 193 (Motter and Ahern, 2012), and so we compared fatty activation of mTRPA1 with that of hTRPA1 194 under our experimental conditions. In these experiments the effects of fatty acids were 195 normalized to the effect produced by a high $(300 \mu \mathrm{M})$ concentration of $\mathrm{CA}$, to control for any 196 differences between the number of channels expressed in the mTRPA1 and hTRPA1 cell lines. 197 AA $(100 \mu \mathrm{M})$ produced an increase in $[\mathrm{Ca}]_{\mathrm{i}}$ that was $74 \pm 12 \%$ of that CA at hTRPA1, and $81 \pm$ $1984 \%$ at mTRPA1 ( $\mathrm{n}=5$ each, $\mathrm{P}>0.6)$. Both DHA $(100 \mu \mathrm{M}, 51 \pm 7 \%$ and $32 \pm 6 \%$ of CA at 199 hTRPA1 and mTRPA1 respectively, $\mathrm{P}=0.125)$ and $\omega 3$-AA $(100 \mu \mathrm{M}, 16 \pm 5 \%$ and $5 \pm 2 \%$ of 200 CA at hTRPA1 and mTRPA1 respectively) activated TRPA1 less than the equivalent 201 concentration of AA.

202 Amino acid/neurotransmitter conjugates of arachidonic acid are a large group of AA derivatives 203 with an incompletely characterized pharmacology. The prototypic NAAN, $N$-arachidonoyl 204 glycine (NA-Gly) produced modest activation of hTRPA1 at the highest concentration tested (30 $205 \mu \mathrm{M}$ ), while the structurally similar endocannabinoid arachidonoyl ethanolamide (anandamide, $206 \mathrm{C} 20: 4 \omega 6)$, robustly activated the channel $\left(227 \pm 42 \%\right.$ increase in $[\mathrm{Ca}]_{\mathrm{i}}$, at $30 \mu \mathrm{M}$, Figure 1 , (De 207 Petrocellis et al., 2009). By contrast, lineoyl ethanolamide (C18:2 $\omega 6)$ was essentially inactive at 
hTRPA1. $N$-arachidonoyl tyrosine (NA-Tyr) also activated TRPA1 to a substantial degree (172 \pm

$20920 \%$ increase in $[\mathrm{Ca}]_{\mathrm{i}}$ at $30 \mu \mathrm{M}$ ) but other NAAN with aromatic head groups, $N$-arachidonoyl

210 dopamine (NA-DA), $N$-oleoyl dopamine (OL-DA) and NA-5HT, were ineffective at $30 \mu \mathrm{M}$

211 (Table 1). $N$-arachidonoyl taurine (NA-Tau) was also a poor activator of TRPA1 (Table 1). OL-

212 DA is also a potent inhibitor of 5-lipoxygenases (Tseng et al., 1992), but it failed to inhibit the

213 effects of AA $(30 \mu \mathrm{M})$, the elevation of $[\mathrm{Ca}]_{\mathrm{i}}$ was $115 \pm 9 \%$ by AA alone, and $148 \pm 20 \%$ in the

214 presence of $30 \mu \mathrm{M}$ OL-DA.

215 AA is unlikely to activate TRPA1 by covalent modification so we sought to determine whether

216 there were differences between AA and CA activation of TRPA1. We first assessed whether AA

217 and CA could activate the channel in a synergistic manner. Prior administration of subthreshold

218 doses of AA $(100 \mathrm{nM}, 300 \mathrm{nM}$ or $1 \mu \mathrm{M})$ failed to affect the concentration relationship of 219 subsequently applied CA (1 $\mu \mathrm{M}$ to $300 \mu \mathrm{M}$, Figure 5).

220 We next assessed whether activation of TRPA1 by high concentrations of either AA or CA

221 affected the response to a subsequent addition of the other agonist. Application of either drug

222 produced a robust increase in $[\mathrm{Ca}]_{\mathrm{i}}$ which declined over the next 15 to 20 minutes. Addition of

$223 \mathrm{CA}(300 \mu \mathrm{M})$ after 30 minutes of $\mathrm{AA}(100 \mu \mathrm{M})$ produced a very small increase in $[\mathrm{Ca}]_{\mathrm{i}}$, as did

224 another addition of AA $(100 \mu \mathrm{M})$ at this point. Similarly, application of AA (100 $\mu \mathrm{M})$ following

$225 \mathrm{CA}(300 \mu \mathrm{M})$ also produced only a small increase in $[\mathrm{Ca}]_{i}$. Thus, each agent produced essentially

226 complete cross-desensitization to the other (Figure 5, Table 2). Ionomycin $(30 \mu \mathrm{M})$ administered

22730 minutes after the addition of AA $(100 \mu \mathrm{M})$ produced an increase in $[\mathrm{Ca}]_{\mathrm{i}}$ of $1730 \pm 45 \%$,

228 similar to the elevation of $[\mathrm{Ca}]_{\mathrm{i}}$ seen when ionomycin $30 \mu \mathrm{M}$ is added 30 minutes after a solvent

229 blank $(1390 \pm 15 \%)$. This indicates that the reduced responses to AA and CA after 
230 desensitization were not due to non-specific effects of prolonged elevations of $[\mathrm{Ca}]_{\mathrm{i}}$ on the

231 fluorescent dye or cells.

232 Previous studies have identified 3 intracellular, N-terminal cysteine residues required for

233 hTRPA1 activation by CA (Hinman et al., 2006). We examined the effects of mutating all of

234 these residues, Cys 621, Cys 641 and Cys 665 to serine on the activation of hTRPA1 by AA. As

235 previously reported (Hinman et al., 2006), application of CA to the 3x Cys mutant hTRPA1

236 produced essentially no activation of the channel (Figure 6). By contrast, the effects of AA were

237 reduced but not abolished in the 3x Cys mutant hTRPA1 (Figure 6). In these studies we extended

238 the AA concentration response curve to include a concentration of $100 \mu \mathrm{M}$, the resulting $\mathrm{EC}_{50}$ in

239 wt hTRPA1 was $13 \pm 4 \mu \mathrm{M}$, with a maximum increase in fluorescence of $390 \pm 70 \%$. AA (100

$240 \mu \mathrm{M}$ ) increased fluorescence in $3 x$ Cys mutant hTRPA1 by $155 \pm 30 \%$. NPPB is another agonist

241 of TRPA1 which does not bind to the reactive cysteine residues (Liu et al., 2010), NPPB-induced

242 elevations of calcium were also reduced but not abolished in the $3 \mathrm{x}$ cysteine mutant of hTRPA1

243 (Figure 6). These data suggest that mutation of the cysteine residues can reduce but not abolish

244 the activation of TRPA1 by unreactive compounds not structurally related to AA.

\section{DISCUSSION}

246 The principle finding of our study is that AA and NAANs activate human TRPA1, although

247 NAAN do so less effectively than AA. The activation of TRPA1 by AA and related compounds

248 has a distinct profile from that reported for these compounds at other ion channels such as

249 TRPV1 or Cav3 calcium channels. We also found that the AA activation of TRPA1 is only

250 partially dependent on the presence of $3 \mathrm{~N}$-terminal intracellular Cys residues that are required

251 for activation of the channel by reactive electrophiles such as cinnamaldehyde. Our data is 252 broadly consistent with studies reporting that AA (10 $\mu \mathrm{M}$, Bandell et al., 2004) and 
253 docosohexanoic acid (Motter and Ahern, 2012) activate rodent TRPA1, but there appear to be 254 differences in the effects of fatty acids and related compounds at human TRPA1.

255 We are confident that the effects of AA were being mediated by direct activation of TRPA1, and 256 not by AA metabolites or though unspecific actions of AA on $[\mathrm{Ca}]_{\mathrm{i}}$. Under our experimental 257 conditions, AA produced negligible increases in $[\mathrm{Ca}]_{i}$ in untransfected HEK 293 cells, or in HEK 258293 cells where TRPA1 expression had not been induced by tetracycline. Further, the effects of 259 AA were blocked by specific (HC-030031, McNamara et al., 2007) and non-specific (ruthenium 260 red) TRPA1 antagonists. AA is the parent molecule of a number of reactive compounds that can 261 activate TRPA1 (e.g. Materazzi et al., 2008; Taylor-Clark et al., 2008; Gregus et al., 2012; 262 Sisignano et al., 2012), however, the effects of AA were not modified by preincubation of HEK 263293 cells with inhibitors of cyclo-oxygenase, lipoxygenase and FAAH, making it likely that AA 264 itself was activating TRPA1. It is worth noting that the potency of AA to activate hTRPA1 is 265 very similar to those of prostaglandin-derived TRPA1 agonists identified in previous studies 266 (Taylor-Clarke et al., 2008; Materazzi et al., 2008), but it is significantly less potent than 267 hepoxilin A3 (Gregus et al., 2012) or 5,6 epoxyeicosatrienoic acid (Sisignano et al., 2012). Thus, 268 metabolism of AA by 12-lipoxygenase or cytochrome P450 epoxygenase may increase the tissue 269 availability of TRPA1 activators, while metabolism via cyclooxygenase is unlikely to, unless the 270 derivatives were substantially more stable than AA, or if they were selectively available in a 271 tissue compartment where AA levels were low.

272 Arachidonic acid was the most potent activator of hTRPA1 of the fatty acids we examined. In a 273 study published while the present work was in preparation, Motter and Ahern (2012) used 274 electrophysiological techniques to examine the effects of fatty acids on TRPA1. They focussed 275 on docosahexaenoic acid as their reference compound. DHA activated rTRPA1 with an $\mathrm{EC}_{50}$ 
276 between 11 and $40 \mu \mathrm{M}$, depending on the membrane potential where inhibition was measured.

277 At a concentration of $100 \mu \mathrm{M}$, AA produced a similar increase in current to DHA, and this 278 increase was similar to that produced by a high concentration of AITC (1 mM), a covalent

279 TRPA1 agonist. In our experiments, which measured elevations in $[\mathrm{Ca}]_{\mathrm{i}}$ produced by activation 280 of hTRPA1, the $\mathrm{EC}_{50}$ of $\mathrm{AA}$ was about $10 \mu \mathrm{M}$. Interestingly, at $100 \mu \mathrm{M}$, DHA produced 281 significantly less activation of both human and mouse TRPA1 than AA, while adrenic acid 282 (C22:4) was inactive. Fatty acids with shorter acyl chains were also much less active than AA. 283 We also found that $\omega 3$-AA was much less effective than $\omega 6$-AA at both human and mouse 284 TRPA1. Interestingly, the carboxylic acid moiety of AA appears to be unnecessary for activation 285 of TRPA1, as AA-ME was almost as equally effective as AA, and arachidonoyl ethanolamide and 286 other NAAN retained substantial TRPA1 agonist activity.

287 Motter and Ahern (2012) did not directly compare the potencies of different fatty acids at TRPA1, 288 and our results are largely consistent with theirs, with the exception of the relatively low activity 289 of $\omega 3 \mathrm{AA}$ in the present study. It should be emphasized that there are significant differences in 290 the methodology between the two studies. Firstly, our population measurements of TRPA1 291 activation were conducted at physiological temperature $\left(37^{\circ} \mathrm{C}\right)$, a temperatures close to that at 292 which TRPA1 undergoes temperature-dependent inactivation (Wang et al., 2012), while the study 293 of Motter and Ahern was done at room temperature, conditions which may favour ligand 294 activation of the channel. Secondly, our work measures both calcium influx through TRPA1 and 295 any subsequent release of intracellular calcium or calcium entry from outside the cell produced 296 by this, which may have an amplifying effect on the signal. Thirdly, our studies were done with 297 the membrane potential of the cells free to vary between the resting potential of CHO cells and 298 the reversal potential of TRPA1 (around $0 \mathrm{mV}$ ), the study of Motter and Ahern (2012) showed 
some voltage-dependence in the potency of DHA, with the compound being more potent at

300 highly depolarized potentials. Finally, our work is done in intact cells, which may allow distinct

301 mechanisms of channel modulation to those happening in cells subject to whole cell patch-clamp

302 recordings. Nevertheless, despite the recognized differences in pharmacology between rodent

303 and human TRPA1, arachidonic acid and related compounds appear to act in a qualitatively

304 similar manner.

$305 \mathrm{~N}$-acyl amino acids are a large family of lipid mediators that affect a variety of ion channels and

306 receptors important for nociception (Connor et al., 2010). None of the NAAN tested in the

307 present study were as effective as AA or AEA in activating TRPA1. The most effective was NA-

308 Tyr, with NA-Gly and NA-Tau being less and active and NA-DA, NO-DA and NA-5HT being

309 essentially inactive. This profile is quite distinct from that of these compounds at other well

310 characterized effectors, TRPV1 and $\mathrm{Ca}_{\mathrm{v}} 3$ channels. Notably, NA-DA and NO-DA are agonists at

311 TRPV1 (De Petrocellis et al., 2004), while NA-5HT and NA-Tyr are antagonists (Maione et al.,

312 2007, Connor et al unpublished observations). Neither NO-DA nor NA-5HT inhibited the effects

313 of AA at hTRPA1, suggesting that they interact with TRPA1 very weakly if at all. When

314 considering NAAN modulation of $\mathrm{Ca}_{\mathrm{v}} 3$ channels, both NA-5HT and NA-DA inhibit these

315 channels with sub-micromolar potencies, as does AEA (Chemin et al., 2001; Ross et al., 2009,

316 Gilmore et al., 2012). AA also inhibits Cav3 channels, but less potently than AEA, NA-5HT or

317 NA-DA (Chemin et al., 2007; Ross et al., 2009, Gilmore et al., 2012). The rank order of

318 effectiveness for fatty acid inhibition of human $\mathrm{Ca}_{\vee} 3$ channels, $\mathrm{C} 22: 6 \approx \mathrm{C} 22: 4 \approx \mathrm{C} 20: 4>\mathrm{C} 20: 2>$

319 C20:1 > C20:4-methyl ester; Chemin et al; 2007) is quite distinct from that for activation of

320 TRPA1, where $\mathrm{C} 20: 4 \geq \mathrm{C} 20: 4$-methyl ester $>\mathrm{C} 22: 6>>\mathrm{C} 22: 4 \approx \mathrm{C} 20: 2 \approx \mathrm{C} 20: 1$. The binding site

321 for AA and related compounds has not been identified on either TRPA1 or $\mathrm{Ca}_{\mathrm{v}} 3$ channels, but the

322 distinct ligand/activity profiles at these channels suggests specific sites of interaction rather than 
323

324 effects of the membrane fluidity-modifying detergent Triton-X 100 on TRPA1 (Motter and Ahern 325 2012).

326 Several regions of TRPA1 have been shown to interact with ligands. The N-terminal ankyrin 327 repeat domain of hTRPA1 is of major importance for the binding of reactive compounds, with 328 three specific cysteine residues, Cys 621, Cys 641 and Cys 665 identified as crucial for channel 329 activation by AITC and cinnamaldehyde (Hinman et al; 2006). Mutation of these cysteines and 330 lysine 708 also prevented activation of TRPA1 by 4-hydroxynonenol (Trevisani et al., 2007) By 331 contrast, menthol and thymol agonist activity is dependent on specific residues in the fifth 332 transmembrane domain (TM5) of hTRPA1 (Xiao et al., 2008) while the channel domains 333 required for hTRPA1 activation by NPPB and farnesyl thiosalicylic acid remain incompletely 334 defined. AA most resembled NPPB in that it retained significant activity in hTRPA1 where 335 Cys621, Cys641 and Cys 665 had been mutated to serine. This channel was largely insensitive to 336 CA. The requirement for intact Cys621/641/665 for full agonist activity of AA and NPPB has not 337 been reported before, but likely reflects the importance of Cys-Cys cross-links involving Cys621 338 and Cys665 and other N-terminal Cys residues in maintaining the conformation of TRPA1 (Wang 339 et al., 2012), rather than indicating that AA or NPPB covalently modify hTRPA1. Our data are 340 consistent with those of Motter and Ahern (2012), who showed that the presence of the N341 terminal domain of murine TRPA1 was necessary but not sufficient for activation of 342 mouse/drosophila TRPA1 chimeras.

343 Arachidonic acid is major signalling molecule derived from the actions of phospholipase $\mathrm{A}_{2}$ on 344 membrane phospholipids, and it acts directly on a diverse range of ion channels as well as serving 345 as a precursor for a host of other molecules which activate or inhibit ion channels. Based on the 
346 affinity of AA for cyclooxygenase and lipoxygenase enzymes it has been suggested that

347 concentrations of AA up to about $30 \mu \mathrm{M}$ may be physiologically relevant (Attwell et al., 1993).

348 TRPA1 is strongly expressed in subpopulations of sensory neurons and various epithelial cells

349 throughout the body (Bodkin and Brain, 2011). There is also evidence for TRPA1-mediated

350 modulation of neurotransmission in brain (Shigetomi et al., 2011). Thus, AA actions at TRPA1

351 could potentially modulate peripheral nociception, central neurotransmission as well as lung,

352 bladder and cardiovascular function. Our data suggests that there is a specific site where long

353 chain fatty acids or endocannabinoids can interact with and activate TRPA1. Whether this site is

354 the same as that utilized by arachidonic-acid derived molecules is unknown, although it is

355 tempting to speculate that there may be an agonist site utilized by AA that may also provide a

356 binding pocket for AA-derivatives such as 5,6 EET to facilitate their access to the N-terminal Cys

357 residues of TRPA1 required for their activity (Sisignano et al., 2012). The definition of the AA

358 binding determinants of TRPA1 may provide insights not only into how this channel is activated,

359 but also how novel antagonists may be developed. 


\section{References}

361 Alexander SPH, Mathie A, Peters JA. 2011. Guide to receptors and channels (GRAC), 5th 362 edition. British Journal of Pharmacology 164 (Suppl. 1):S1-S324.

363 Alpizar YA, Gees M, Sanchez A, Apetrei A, Voets T, Nilius B, Talavera K. 2013. Bimodal effects

364 of cinnamaldehyde and camphor on mouse TRPA1.

365 Pflügers Archiv - European Journal of Physiology 465: 853-64.

366 Attwell D, Miller B, Sarantis M. 1993. Arachidonic acid as a messenger in the central nervous 367 system. Seminars in the Neurosciences 5: 159-69.

368 Bandell M, Story GM, Hwang SW, Viswanath V, Eid SR, Petrus MJ, Earley TJ, Patapoutian A. 369 2004. Noxious cold ion channel TRPA1 is activated by pungent compounds and bradykinin. 370 Neuron 41:849-57.

371 Bautista DM, Jordt SE, Nikai T, Tsuruda PR, Read AJ, Poblete J, Yamoah EN, Basbaum AI,

372 Julius D. 2006. TRPA1 mediates the inflammatory actions of environmental irritants and 373 proalgesic agents. Cell 124:1269-1282.

374 Bodkin JV, Brain SD. 2011. Transient receptor potential ankyrin 1: emerging pharmacology and 375 indications for cardiovascular biology. Acta Physiologica 293: 87-98.

376 Chemin J, Monteil A, Perez-Reyes E, Nargeot J, Lory P. 2001. Direct inhibition of T-type calcium 377 channels by the endogenous cannabinoid anandamide. EMBO J 20:7033-7040. 
378 Chemin J, Nargeot J, Lory P. 2007. Chemical determinants involved in anandamide-induced 379 inhibition of T-type calcium channels. Journal of Biological Chemistry 282:2314-2323.

380 Cho JH, Jeong MY, Choi IS, Lee HJ, Jang IS. 2012. TRPA1-like channels enhance glycinergic 381 transmission in medullary dorsal horn neurons. Journal of Neurochemistry 122:691-701.

382 Connor M, Vaughan CW, Vandenberg R. 2010. $N$-Acyl amino acids and $N$-acyl neurotransmitter 383 conjugates: neuromodulators and probes for new drug targets. British Journal of Pharmacology $384160: 1857-1871$.

385 Corey DP, Garcia-Anoveros J, Holt JR, Kwan KY, Lin S-Y, Vollrath MA, Amalfitano A, Cheung 386 EL, Derfler BH, Duggan A, Geleoc GS, Gray PA, Hoffman MP, Rehm HL, Tamasauskas D, 387 Zhang DS. 2004. TRPA1 is a candidate for the mechanosensitive transduction channel of 388 vertebrate hair cells. Nature 432:723-730.

389 De Petrocellis L, Chu CJ, Moriello AS, Kellner JC, Walker JM, Di Marzo V. 2004. Actions of 390 two naturally occurring saturated $\mathrm{N}$-acyldopamines on transient receptor potential vanilloid 1 391 (TRPV1) channels. British Journal of Pharmacology 143:251-256.

392 De Petrocellis L, Di Marzo V. 2009. Role of endocannabinoids and endovanilloids in $\mathrm{Ca}^{2+}$ 393 signalling. Cell Calcium 45:611-624.

394 Gilmore AJ, Heblinski M, Reynolds A, Kassiou M, Connor M. 2012. Inhibition of human 395 recombinant T-type calcium channels by $N$-arachidonoyl 5-HT. British Journal of Pharmacology $396 \quad$ 167:1076-1088. 
397 Gregus AM, Doolen S, Dumlao DS, Buczynski MW, Takasusuki T, Fitzsimmons BL, Hua XY, 398 Dennis EA, Yaksh TL. 2012. Spinal 12-lipoxygenase-derived hepoxilin A3 contributes to the 399 inflammatory hyperalgesia via activation of TRPV1 and TRPA1 receptors. Proceedings of the 400 National Acadamy of Sciences USA 109:6721-6726.

401 Hamill OP, Marty A, Neher E, Sakmann B, Sigworth FJ. 1981. Improved patch-clamp techniques 402 for high-resolution current recording from cells and cell-free membrane patches. Pflugers Archiv $403 \quad 391: 85-100$.

404 Hinman A, Chuang HH, Bautista DM, Julius D. 2006. TRP channel activation by reversible 405 covalent modification. Proceedings of the National Acadamy of Sciences USA 103:19564-19568.

406 Jordt SE, Bautista DM, Chuang HH, McKemy DD, Zygmunt PM, Hogestatt ED, Meng ID, Julius 407 D. 2004. Mustard oils and cannabinoids excite sensory nerve fibres through the TRP channel 408 ANKTM1. Nature 427:260-265.

409 Karashima Y, Damann N, Prenen J, Talavera K, Segal A, Voets T, Nilius B. 2007 Bimodal action 410 of menthol on the transient receptor potential channel TRPA1. Journal of Neuroscience $411 \quad 12 ; 27(37): 9874-84$.

412 Koshihara Y, Neichi T, Murota S, Lao A, Fujimoto Y, Tatsuno T. 1983. Selective inhibition of 5413 lipoxygenase by natural compounds isolated from Chinese plants, Artemisia rubripes Nakai. 414 FEBS Letters 158:41-44. 
415 Liu K, Samuel M, Ho M, Harrison RK, Paslay JW. 2010. NPPB structure-specifically activates

416 TRPA1 channels. Biochemical Pharmacology 80:113-121.

\begin{abstract}
417 McNamara CR, Mandel-Brehm J, Bautista DM, Siemens J, Deranin KL, Zhao M, Hayward NJ, 418 Chong JA, Julius D, Moran MM, Franger CM. 2007. TRPA1 mediates formalin-induced pain. 419 Proceedings of the National Acadamy of Sciences USA 104:13525-30.
\end{abstract}

420 Macpherson LJ, Dubin AE, Evans MJ, Marr F, Schultz PG, Cravatt BF, Papoutian A. 2007. 421 Noxious compounds activate TRPA1 ion channels through covalent modification of cysteines. 422 Nature 445:541-545.

423 Maione S, De Petrocellis L, de Novellis V, Moriello AS, Petrosino S, Palazzo E, Rossi FS, 424 Woodward DF, Di Marzo V. 2007. Analgesic actions of N-arachidonoyl-serotonin, a fatty acid 425 amide hydrolase inhibitor with antagonistic activity at vanilloid TRPV1 receptors. British 426 Journal of Pharmacology 150:766-781.

427 Materazzi S, Nassini R, Andre E, Campi B, Amadesi S, Trevisani M, Bunnett NW, Patacchini R, 428 Geppetti P. 2008. Cox-dependent fatty acid metabolites cause pain through activation of the 429 irritant receptor TRPA1. Proceedings of the National Acadamy of Sciences USA 105:1204543012050.

431 Motter AL, Ahern GP. 2012. TRPA1 Is a Polyunsaturated Fatty Acid Sensor in Mammals. PLoS 432 One.;7(6):e38439. 
433 Nagata K, Duggan A, Kumar G, Garcia-Anoveros J. 2005. Nociceptor and hair cell transducer

434 properties of TRPA1, a channel for pain and hearing. Journal of Neuroscience 25:4052-4061.

\begin{abstract}
435 Ross HR, Gilmore AJ, Connor M. 2009. Inhibition of human recombinant T-type calcium 436 channels by the endocannabinoids arachidonyl dopamine. British Journal of Pharmacology $437 \quad 156: 740-750$.
\end{abstract}

438 Shigetomi E, Tong X, Kwan KY, Corey DP, Khakh BS. 2011. TRPA1 channels regulate astrocyte 439 resting calcium and inhibitory synapse efficacy through GAT-3. Nature Neuroscience 15: 70-80.

440 Sisignano M, Park C-Y, Angioni C, Zhang DD, von Hehn C, Cobos EJ, Ghasemiou N, Xu ZZ, 441 Kumaran V, Lu R, Grant A, Fischer MJ, Schmidtko A, Reeh P, ji RR, Woolf CJ, Geisslinger G, 442 Scholich K, Brenneis C. 2012. 5,6-EET is released upon neuronal activity and induces 443 mechanical pain hypersensitivity via TRPA1 on central afferent terminals. Journal of 444 Neuroscience 32:6364-6372.

445 Story GM, Peier AM, Reeve AJ, Eid SR, Mosbacher J, Hricik TR, Earley TJ, Hergarden AC, 446 Andersson DA, Hwang SW, McIntyre P, Jegla T, Bevan S, Patapotian A. 2003. ANKTM1, a 447 TRP-like channel expressed in nociceptive neurons, is activated by cold temperatures. Cell $448 \quad 112: 819-829$.

449 Taylor-Clark TE, Undem BJ, Macglashan DW, Jr., Ghatta S, Carr MJ, McAlexander MA 2008. 450 Prostaglandin-induced activation of nociceptive neurons via direct interaction with transient 451 receptor potential A1 (TRPA1). Molecular Pharmacology 73:274-281. 
452 Trevisani M, Siemens J, Materazzi S, Bautista DM, Nassini R, Campi B, Imamachi N, 453 Pattacchini R, Cottrell GS, Gatti R, Basbaum AI, Bunnet NW, Julius D, Gepetti P. 2007. 4454 hydroxynonenol, an endogenous aldehyde, causes pain and neurogenic inflammation through 455 activation of the irritant receptor TRPA1. Proceedings of the National Acadamy of Sciences USA $456 \quad 104: 13519-13524$.

457 Tseng CF, Iwakami S, Mikajiri A, Shibuya M, Hanaoka F, Ebizuka Y, Padmawinata K, Sankawa 458 U. 1992. Inhibition of in vitro prostaglandin and leukotriene synthesis by cinnamoyl- $\beta$ 459 phenethylamine and N-acyldopamine derivatives. Chemical and Pharmaceutical Bulletin $460 \quad 40: 396-400$.

461 Vane JR. 1971. Inhibition of prostaglandin synthesis as a mechanism of action for aspirin-like 462 drugs. Nature 231: 232-235

463 Wang L, Cvetkov TL, Chance MR, Moisseenkova-Bell VY. 2012. Identification of in vivo 464 disulfide conformation of TRPA1 ion channel. Journal of Biological Chemistry 287:6169-6176.

465 Wang S, Lee J, Ro JY, Chung M-K. 2012. Warmth supresses and desensitizes damage-sensing ion 466 channel TRPA1. Molecular Pain 8:22

467 Wang L., Cvetkov TL., Chance MR., Moiseenkova-Bell VY. 2012. Identification of in vivo 468 disulfide conformation of TRPA1 ion channel. Journal of Biological Chemistry 287(9):6169-76. 
469 Xiao B, Dubin AE, Bursulaya B, Viswanath V, Jegla TJ, Patapoutian A. 2008. Identification of

470 transmembrane domain 5 as a critical molecular determinant of menthol sensitivity in 471 mammalian TRPA1 channels. Journal of Neuroscience 28:9640-9651. 


\section{Figure 1}

Arachidonic acid and related molecules elevate calcium in HEK 293 cells expressing hTRPA1.

Changes in intracellular calcium concentration were determined as outlined in the Methods. (A) Concentration response curves for w6-arachidonic acid (w6-AA), w3-arachidonic acid (w3-AA), arachidonic acid methyl-ester (AA-ME), arachidonic acid ethyl-ester (AA-EE) and cinnamaldehyde (CA) at hTRPA1. Each data point represents the mean \pm s.e.m. of 4-5 determinations in triplicate. The curves for AA and CA essentially overlap. (B) Concentration response curves for anandamide, $\mathrm{N}$-arachidonoyl tyrosine (NA-Tyr), $\mathrm{N}$-arachidonoyl taurine (NA-Tau) and $\mathrm{N}$-arachidonoyl glycine (NA-Gly) at hTRPA1. Each data point represents the mean \pm s.e.m. of 4-5 determinations in triplicate. (C) Representative traces of change in fluorescence produced by concentrations of CA between $1 \mu \mathrm{M}$ and $300 \mu \mathrm{M}$, expressed as raw fluorescence units. CA was applied for the duration of the bar. (D) Representative traces of change in fluorescence produced by $30 \mu \mathrm{M}$ anandamide, arachidonic acid and NA-Tyr, expressed as raw fluorescence units. Drugs were applied for the duration of the bar. 
Figure 1

A

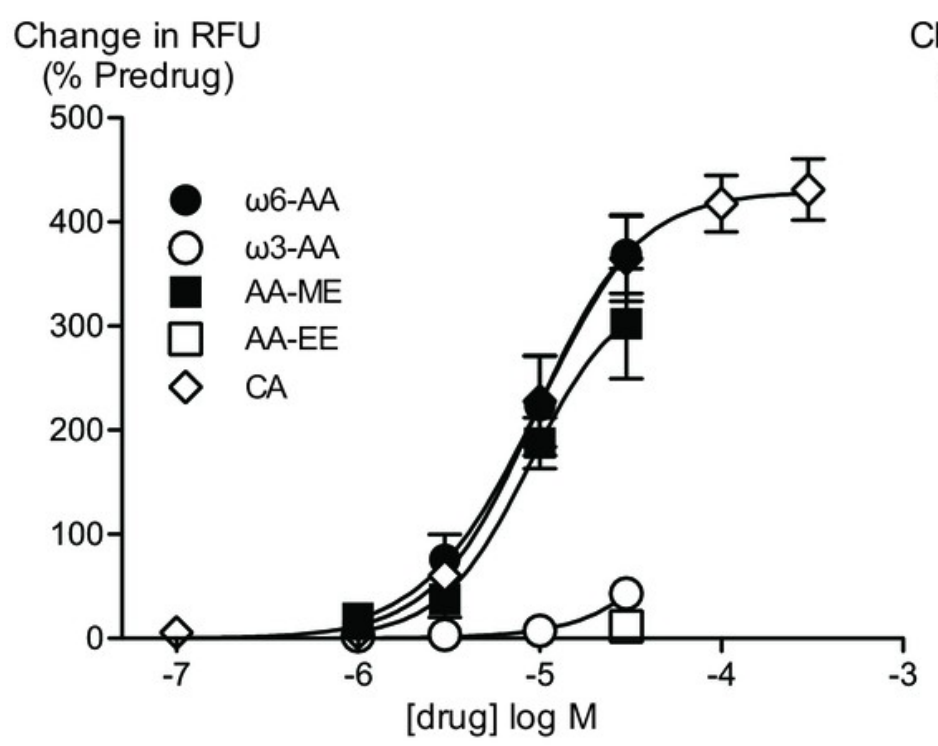

B
Change in RFU

(\% Predrug)

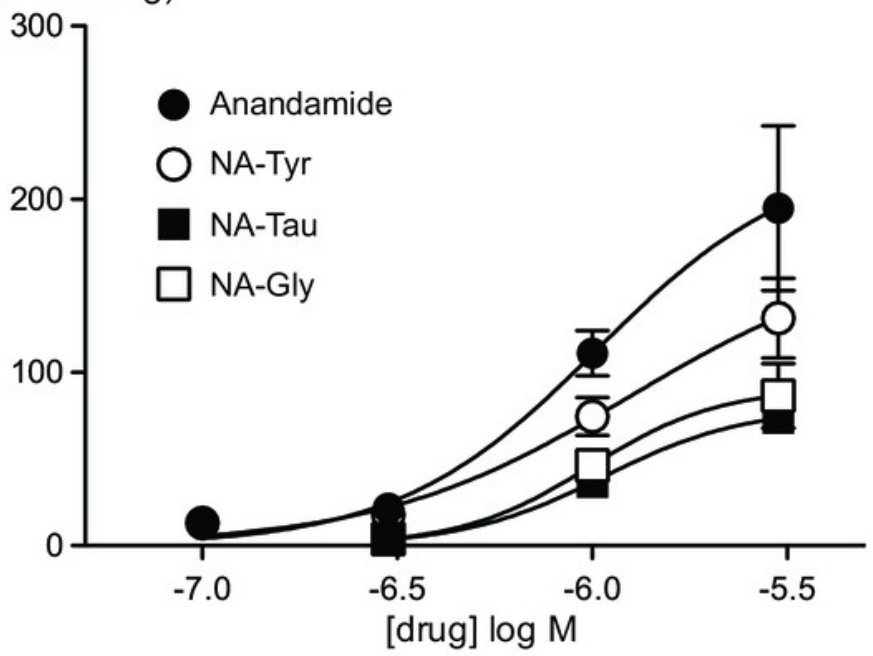

D

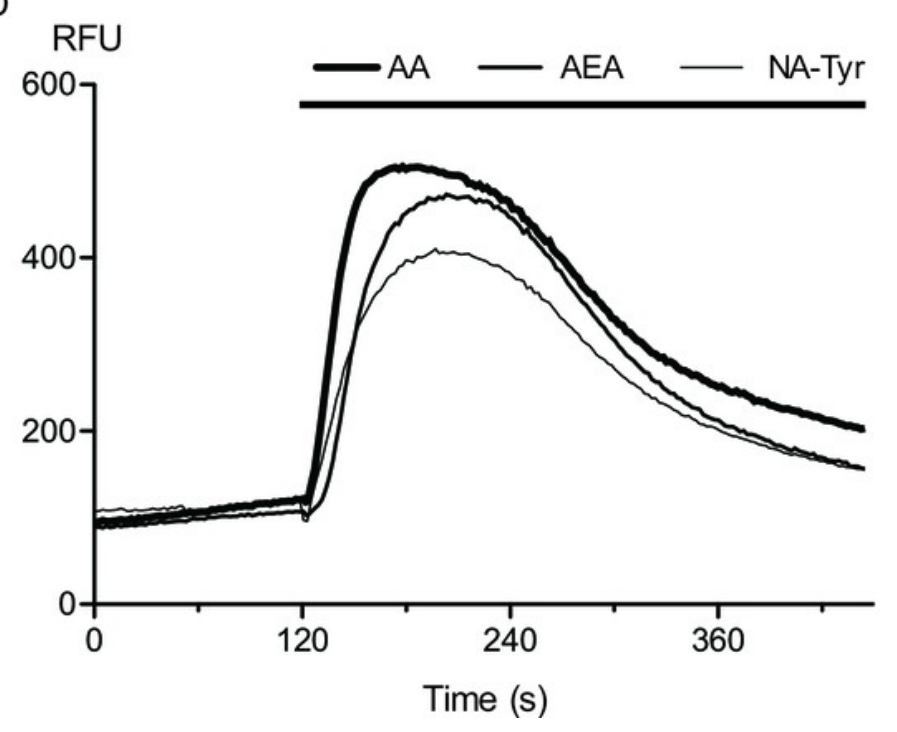




\section{Figure 2}

Arachidonic acid activates hTRPA1.

Changes in intracellular calcium concentration ([Ca $\left.]_{\mathrm{i}}\right)$ was determined as described in the Methods. A) Elevations of $[\mathrm{Ca}]_{i}$ produced by arachidonic acid (AA, $\left.10 \mu \mathrm{M}\right)$ were absent in Flp-In TRex HEK 293 expressing hTRPA1 not induced with tetracycline, and in untransfected Flp-In TRex HEK 293 cells. The effects of AA $(10 \mu \mathrm{M})$ and cinnamaldehyde $(\mathrm{CA}, 30 \mu \mathrm{M})$ were also strongly reduced by ruthenium red $(10 \mu \mathrm{M})$ (representative trace of $A A$ in the presence of RR (B)). HC-030031 (30 $\mu \mathrm{M})$, a specific inhibitor of TRPA1, inhibited the elevations of $(\mathrm{Ca}]_{i}$ produced by arachidonic acid $(\mathrm{C})$ and cinnamaldehyde $(\mathrm{D})$ in an apparently competitive manner. Each point represents the mean \pm s.e.m of at least 4 determinations. Error bars within the point for (C). 
Figure 2
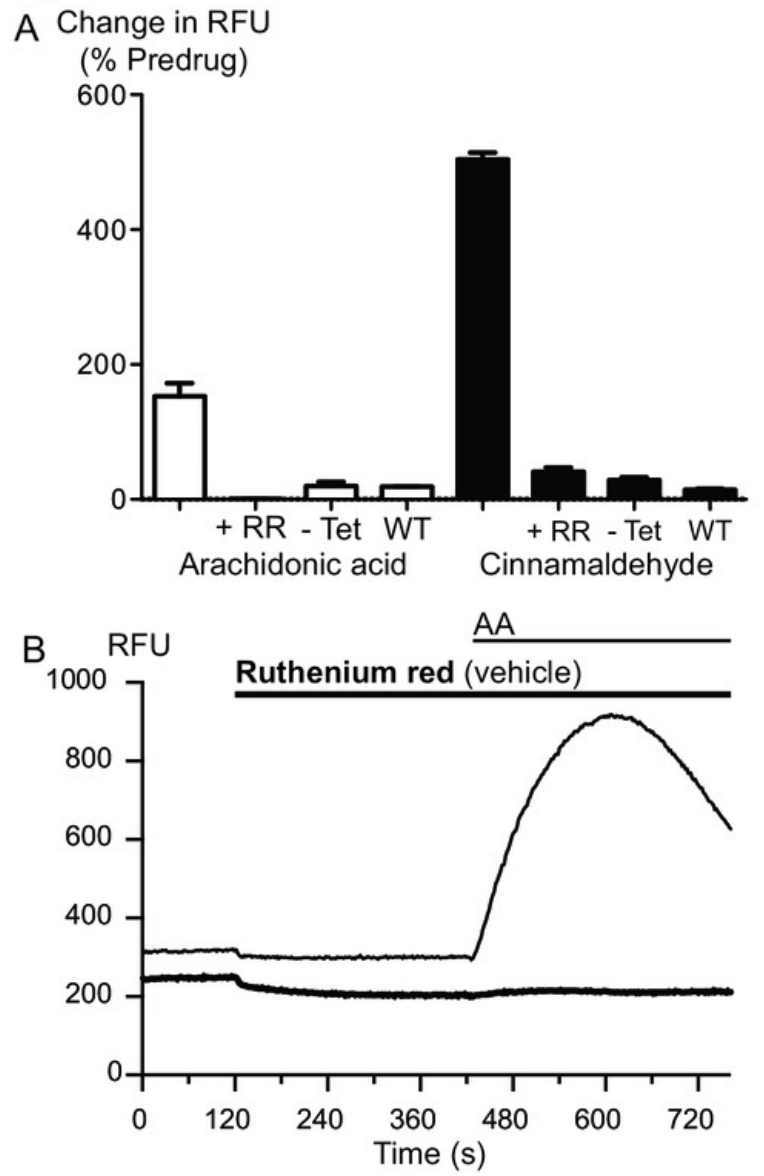

C Change in RFU

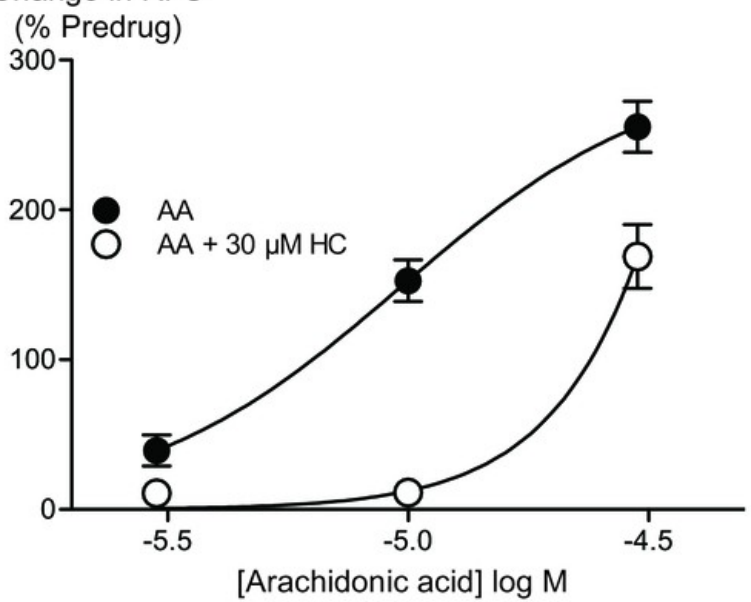

Change in RFU

D (\% Predrug)

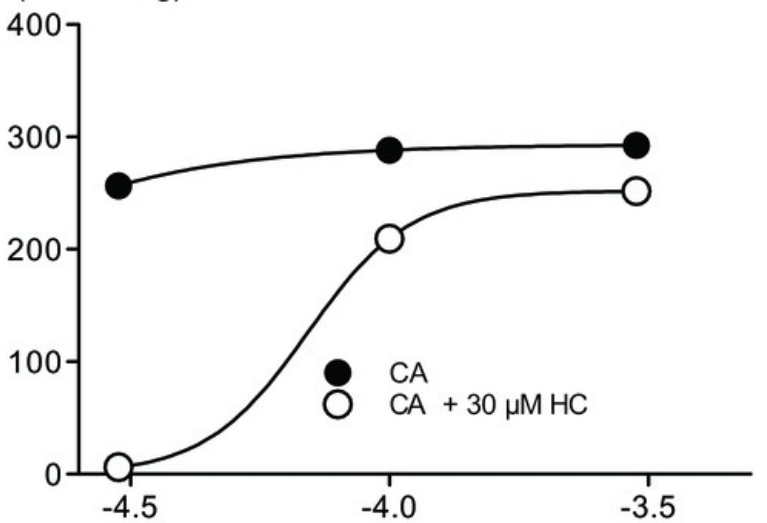

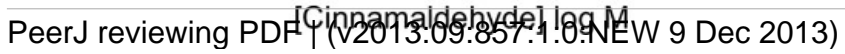




\section{Figure 3}

Arachidonic acid-induced currents in HEK 293 cells expressing hTRPA1.

Whole voltage clamp recordings of membrane currents in HEK 293 cells expressing hTRPA1 were made as outlined in the Methods. A) Current traces from a hTRPA1-expressing HEK 293 cell in control conditions (thin line) and in the presence of $10 \mu \mathrm{M}$ arachidonic acid (AA). Cells were subject to the voltage protocol illustrated beneath the traces. Zero current is designated by the dotted line. B) A plot of the amplitude of the cell current measured at +80 $\mathrm{mV}$ for the same cell, AA was added for the duration of the bar. Typical of 6 similar cells. C) Current traces from a hTRPA1-expressing HEK 293 cell in control conditions (thin line) and in the presence of $100 \mu \mathrm{M}$ cinnamaldehyde (CA). Cells were subject to the voltage protocol illustrated beneath the traces. Zero current is designated by the dotted line. Typical of 5 similar cells. 
Figure 3

A

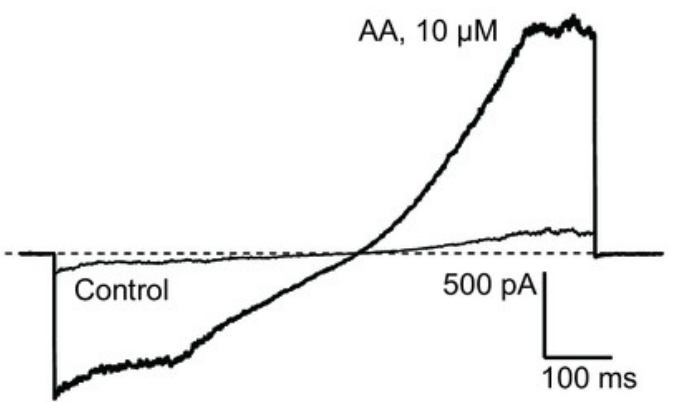

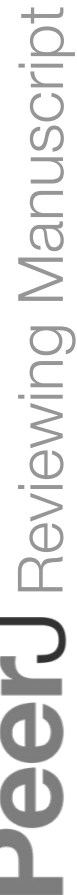
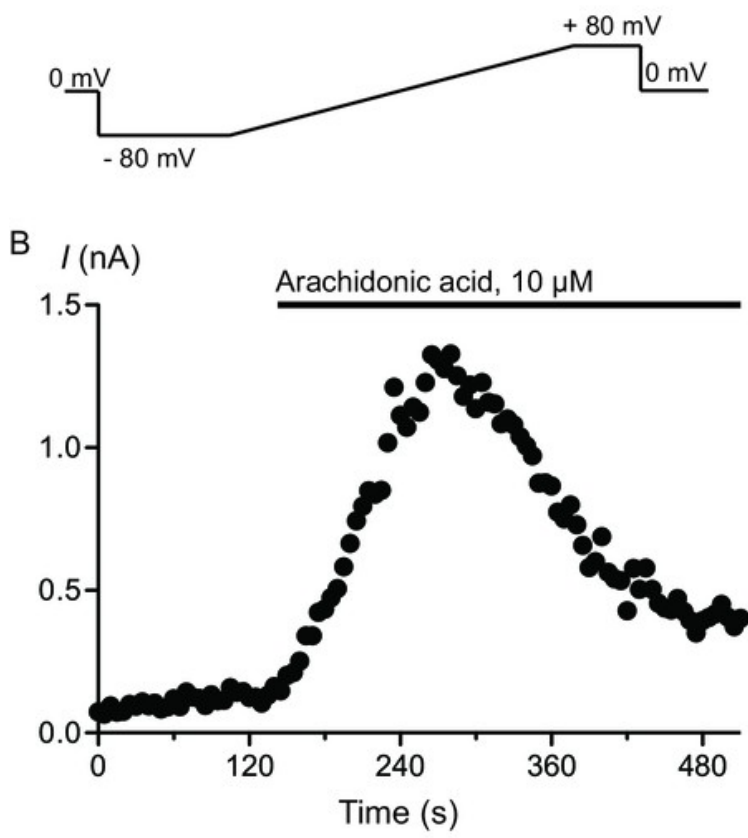

C

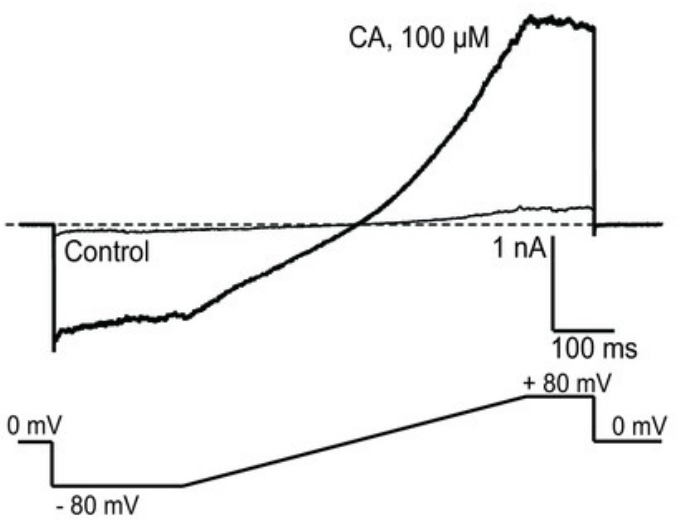




\title{
Figure 4
}

Inhibitors of arachidonic acid metabolism do not affect arachidonic acid activation of TRPA1.

\begin{abstract}
A) Changes in intracellular calcium concentration were determined as described in the Methods. Pre-incubation of cells with inhibitors of lipoxygenase (caffeic acid, $10 \mu \mathrm{M}$ ), fatty acid amide hydrolase ( $N$-arachidonoyl 5-HT, $10 \mu \mathrm{M}$ ) or cyclooxygenase (aspirin, $10 \mu \mathrm{M}$ ) did not affect elevations of $[\mathrm{Ca}]_{i}$ produced by $10 \mu \mathrm{M}$ arachidonic acid through hTRPA1 $(\mathrm{P}>0.35$ for each). Bar graphs represent the mean \pm s.e.m of at least 8 independent determinations per condition. Representative traces for arachidonic acid by itself or in the presence of caffeic acid (B), aspirin (C) and N-arachidonoyl 5-HT (C) provided. They are respectively inhibitors of the lipoxygenase, cyclooxygenase pathways and an inhibitor of fatty acid amid-hydrolase. Each compound was used at $10 \mu \mathrm{M}$.
\end{abstract}


A

Response to $\mathrm{AA}, 10 \mu \mathrm{M}$

(\% Control)

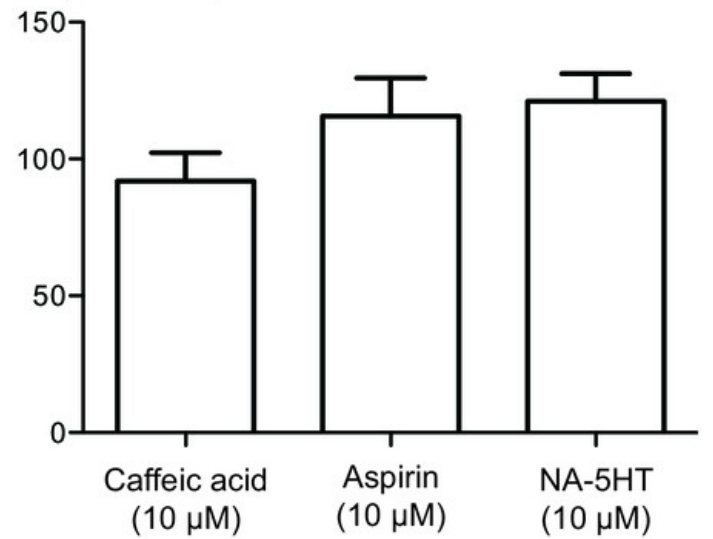

B

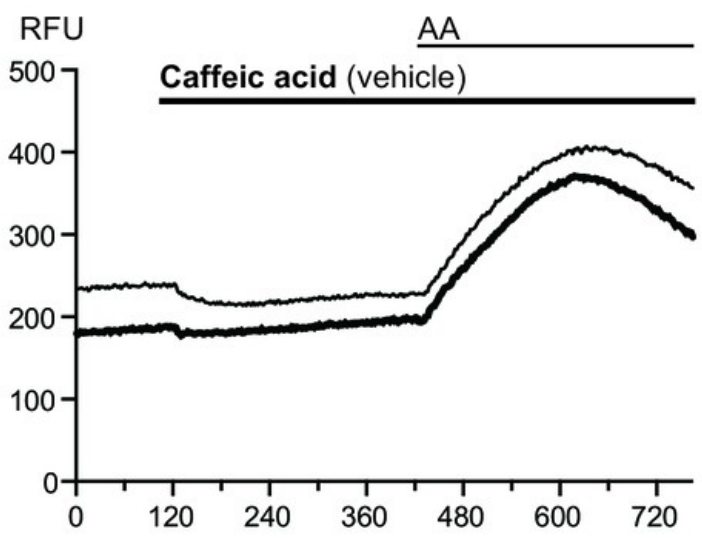

C

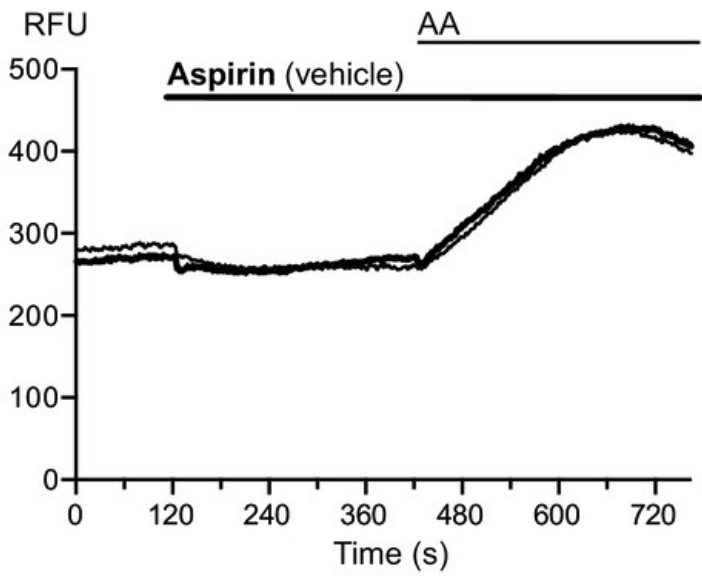

D
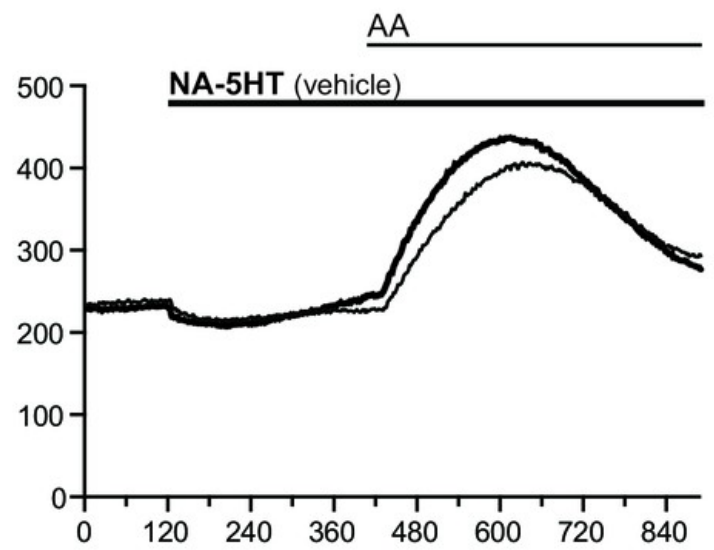

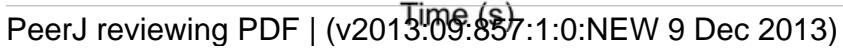




\section{Figure 5}

Lack of interaction between arachidonic acid and cinnamaldehyde in activation of hTPRA1.

Changes in intracellular calcium concentration were determined as outlined in the Methods. A) Concentration response curves for cinnamaldehyde (CA) in control conditions, and in the presence of arachidonic acid (AA, $100 \mathrm{nM}, 1 \mu \mathrm{M})$. Each point represents the mean \pm s.e.m. of 4-5 determinations in triplicate. B) Example traces showing reciprocal crossdesensitization between CA $(300 \mu \mathrm{M})$ and $A A(100 \mu \mathrm{M})$. Drugs were applied for the duration of the bars. Traces represent typical data from 4-5 independent replicates per condition. RFU = raw fluorescence units. 
A

RFU

(\% Predrug Control)

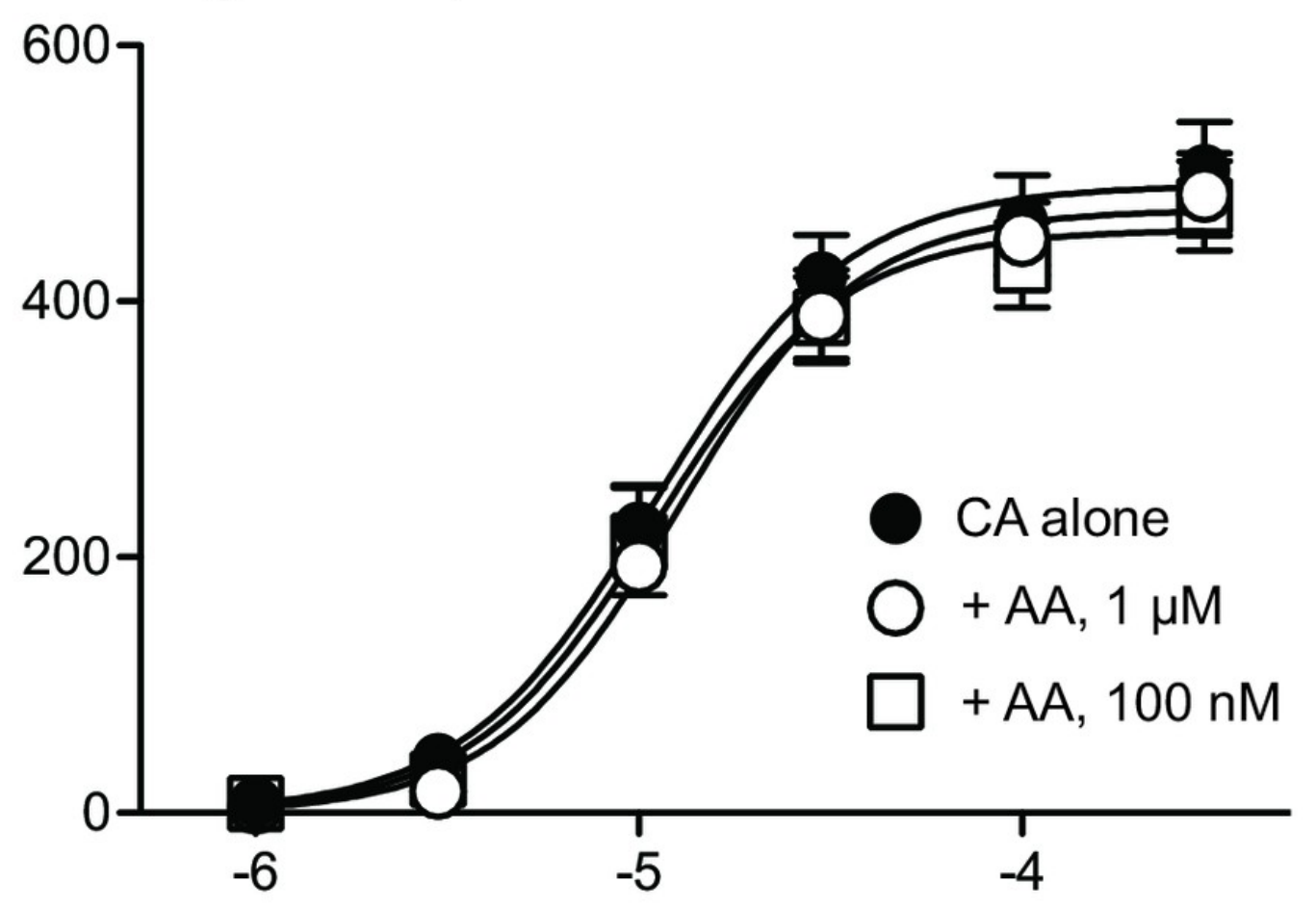

[Cinnamaldehyde] log M

B

RFU

(\% Predrug Control)

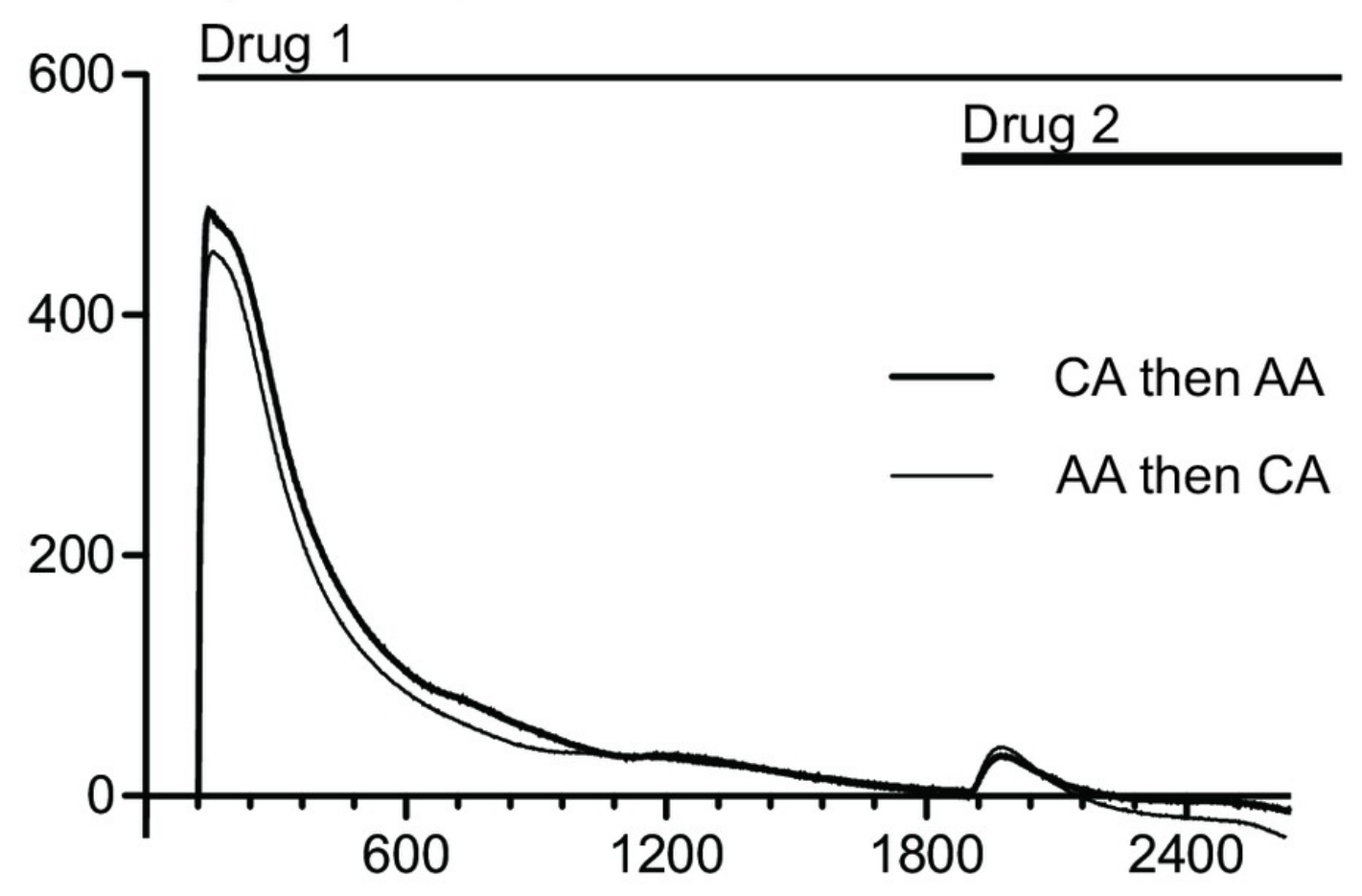




\section{Figure 6}

Distinct amino acid residues in hTRPA1 determine arachidonic acid and cinnamaldehyde activation.

Changes in intracellular calcium concentration were determined as outlined in the Methods. Mutation of Cys621, Cys641 and Cys665 to Ala (3xCys mutant) prevents A) cinnamaldehyde activation of hTRPA1 but only abrogates B) arachidonic acid and C) NPPB activation of the channel. Each point represents the mean \pm s.e.m. of at least 5 independent determinations in triplicate. RFU = raw fluorescence units. 
Figure 6

A

Change in RFU

(\% Predrug)

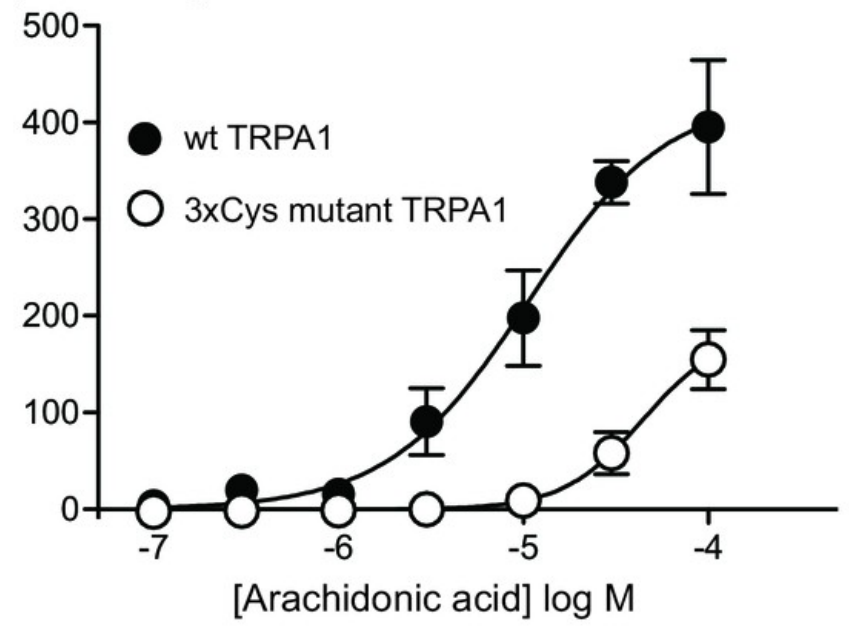

B

Change in RFU

(\% Predrug)

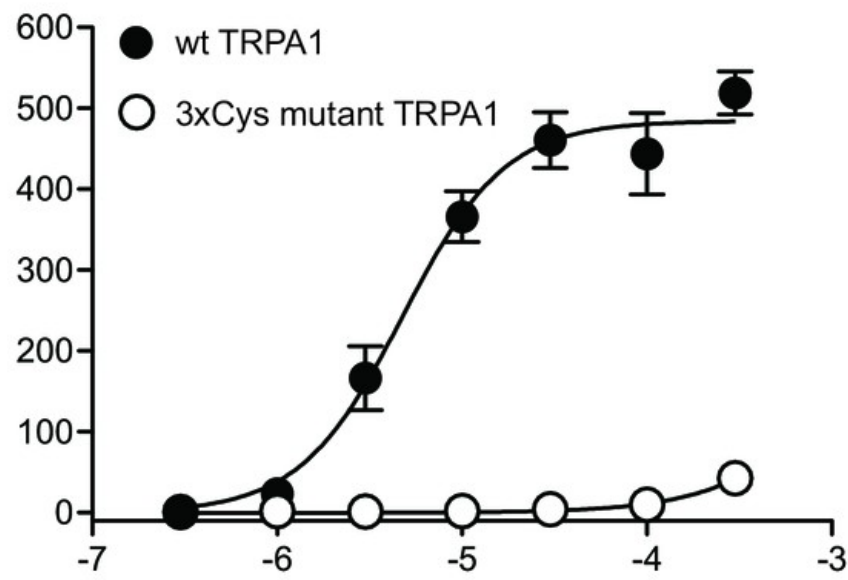

[Cinnamaldehyde] log M

C

Change in RFU

(\% Predrug)

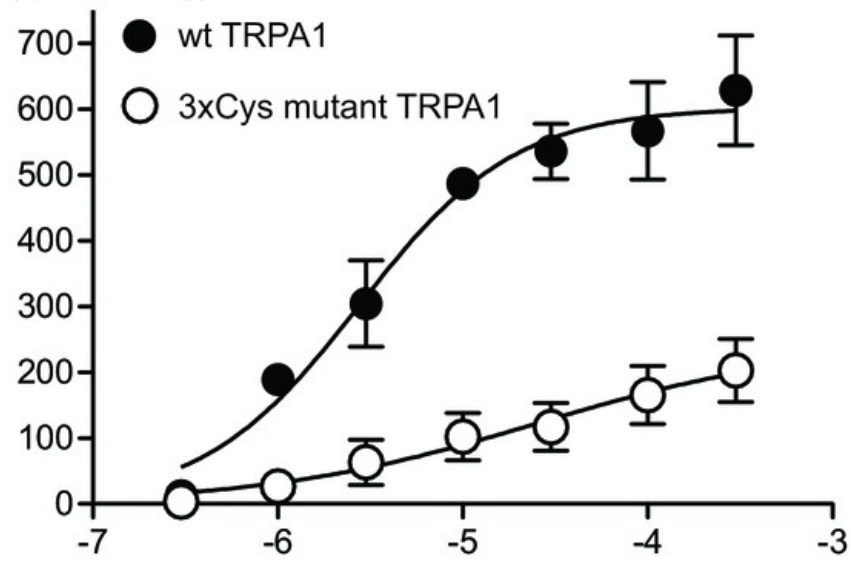

PeerJ reviewing PDF | (v2013:09:857:1:0:New g'Dec 2013) 


\section{Table 1 (on next page)}

Activation of hTRPA1 by arachidonic acid and derivatives.

Changes in intracellular calcium concentration were determined as outlined in the Methods. Each compound was applied to HEK 293 cells expressing hTRPA1 at a concentration of 30 $\mu \mathrm{M}$. Activation of hTRPA1 by cinnamaldehyde was used as a positive control. The values represent the mean \pm s.e.m. of the percent changes in raw fluorescence units, $n=4-5$ determinations per compound. 


\begin{tabular}{|c|c|}
\hline Compound & $\begin{array}{l}\text { Change in RFU } \\
\text { (\% Predrug) }\end{array}$ \\
\hline Cinnamaldehyde $(300 \mu \mathrm{M})$ & ${ }_{426} \pm 28$ \\
\hline $\begin{array}{l}\text { Arachidonic acid } \\
\text { C20:4 } \omega 6\end{array}$ & $369 \pm 38$ \\
\hline $\begin{array}{l}\text { Arachidonic acid } \\
\text { C20:4 } \omega 3\end{array}$ & $43 \pm 10$ \\
\hline $\begin{array}{l}\text { Arachidonic acid } \\
\text { methyl ester }\end{array}$ & $302 \pm 53$ \\
\hline $\begin{array}{l}\text { Arachidonic acid } \\
\text { ethyl ester }\end{array}$ & $12 \pm 4$ \\
\hline $\begin{array}{c}\text { Docosohexaenoic acid } \\
\text { C22:6 } 13\end{array}$ & $121 \pm 24$ \\
\hline $\begin{array}{c}\text { Linoleic acid } \\
\text { C18:2 } \omega 6\end{array}$ & $49 \pm 15$ \\
\hline Arachidonoyl ethanolamide & $195 \pm 48$ \\
\hline Linoleoyl ethanolamide & $12 \pm 5$ \\
\hline $\mathrm{N}$-arachidonoyl tyrosine & $156 \pm 18$ \\
\hline$N$-arachidonoyl taurine & $74 \pm 26$ \\
\hline$N$-arachidonoyl glycine & $87 \pm 19$ \\
\hline$N$-arachidonoyl dopamine & $32 \pm 6$ \\
\hline$N$-oleoyl dopamine & $22 \pm 3$ \\
\hline$N$-arachidonoyl 5-HT & $7 \pm 2$ \\
\hline
\end{tabular}




\section{Table 2 (on next page)}

Activation of hTRPA1 by cinnamaldehyde or arachidonic acid inhibits subsequent agonist activation of the channel.

Changes in intracellular calcium concentration were determined as outlined in the Methods. Maximally effective concentrations of cinnamaldehyde (CA, $300 \mu \mathrm{M})$ or arachidonic acid (AA, $100 \mu \mathrm{M}$ ) were applied to HEK 293 cells expressing hTRPA1. Either CA or AA was then applied 30 minutes later. The first exposure to each agonist essentially abolished the subsequent response. The values represent the mean \pm s.e.m. of the percent changes in raw fluorescence units, $\mathrm{n}=3-5$ determinations per condition. 


\begin{tabular}{|l|l|l|}
\hline Drug Additions & $1^{\text {st }}$ Addition & $2^{\text {nd }}$ Addition \\
& (Change in RFU, \% predrug) $)$ & (Change in RFU, \% predrug) \\
\hline CA then AA & $506 \pm 31$ & $32 \pm 31$ \\
\hline AA then Ca & $486 \pm 47$ & $42 \pm 14$ \\
\hline CA then CA & $560 \pm 20$ & $-3 \pm 6$ \\
\hline AA then AA & $486 \pm 43$ & $57 \pm 44$ \\
\hline
\end{tabular}

